\title{
Co-circulation of three camel coronavirus species and recombination of MERS-CoVs in Saudi Arabia
}

\author{
Jamal S. M. Sabir, ${ }^{1 *}$ Tommy T.-Y. Lam, ${ }^{2,3,4 *}$ Mohamed M. M. \\ Ahmed, ,1,6* Lifeng Li, ${ }^{3,4 *}$ Yongyi Shen, ${ }^{3,4}$ Salah E. M. Abo-Aba, ${ }^{1,7}$ \\ Muhammad I. Qureshi, ${ }^{1}$ Mohamed Abu-Zeid, ${ }^{1,7}$ Yu Zhang, ${ }^{2,3,4}$ \\ Mohammad A. Khiyami, ${ }^{8}$ Njud S. Alharbi, ${ }^{1}$ Nahid H. Hajrah, ${ }^{1}$ \\ Meshaal J. Sabir, ${ }^{1}$ Mohammed H. Z. Mutwakil, ${ }^{1}$ Saleh A. Kabli, ${ }^{1}$ \\ Faten A. S. Alsulaimany, ${ }^{1}$ Abdullah Y. Obaid, ${ }^{9}$ Boping Zhou, ${ }^{2}$ \\ David K. Smith, ${ }^{4}$ Edward C. Holmes, ${ }^{5}$ Huachen Zhu, ${ }^{2,3,4} \uparrow$ Yi \\ $\operatorname{Guan}^{1,2,3,4} \uparrow$
}

'Biotechnology Research Group, Department of Biological Sciences, Faculty of Science, King Abdulaziz University, Jeddah 21589, Saudi Arabia. ${ }^{2}$ State Key Laboratory of Emerging Infectious Diseases (The University of Hong Kong-Shenzhen Branch), Shenzhen Third People's Hospital, Shenzhen, China. ${ }^{3}$ Shantou University-The University of Hong Kong Joint Institute of Virology, Shantou University, Shantou, China. ${ }^{4}$ Centre of Influenza Research and State Key Laboratory of Emerging Infectious Diseases, School of Public Health, The University of Hong Kong, Hong Kong Special Administrative Region, China. ${ }^{5}$ Marie Bashir Institute for Infectious Diseases and Biosecurity, Charles Perkins Centre, School of Biological Sciences and Sydney Medical School, The University of Sydney, Sydney, New South Wales 2006, Australia. ${ }^{6}$ Department of Nucleic Acids Research, Genetic Engineering and Biotechnology Research Institute, City for Scientific Research and Technology Applications, Borg El-Arab, Post Office Box 21934, Alexandria, Egypt. ${ }^{7}$ Microbial Genetics Department, Genetic Engineering and Biotechnology Division, National Research Center, Dokki, Giza, Egypt. ${ }^{8}$ King Abdulaziz City for Science and Technology, Riyadh 11442, Saudi Arabia. ${ }^{9}$ Department of Chemistry, Faculty of Science, King Abdulaziz University, Jeddah 21589, Saudi Arabia.

*These authors contributed equally to this work.

†Corresponding author. E-mail: zhuhch@hku.hk (H.Z.); yguan@hku.hk (Y.G.)

Outbreaks of Middle East respiratory syndrome (MERS) raise questions about the prevalence and evolution of the MERS coronavirus (CoV) in its animal reservoir. Our surveillance in Saudi Arabia in 2014 and 2015 showed that viruses of the MERS-CoV species and a human CoV 229E-related lineage co-circulated at high prevalence, with frequent co-infections in the upper respiratory tract of dromedary camels. Including a betacoronavirus 1 species, we found that dromedary camels share three CoV species with humans. Several MERS-CoV lineages were present in camels, including a recombinant lineage that has been dominant since December 2014 and that subsequently led to the human outbreaks in 2015. Camels therefore serve as an important reservoir for the maintenance and diversification of the MERS-CoVs and are the source of human infections with this virus.

We conducted surveillance for CoVs in dromedary camels in Saudi Arabia, the country most affected by MERS, from May 2014 to April 2015. Initially, paired nasal and rectal swabs were collected from camels at slaughterhouses, farms, and wholesale markets in Jeddah and Riyadh. Because rectal swabs were negative for MERSCoVs (tables S1 and S2), only nasal swabs were subsequently collected at these sites and in Taif (15). Of the 1309 camels tested, $25.3 \%$ were positive for $\mathrm{CoV}$, as established by reverse transcription polymerase chain reaction (RT-PCR) and confirmed by Sanger sequencing. The majority of the CoV-positive camels came from wholesale markets (tables S1 and S2), where indigenous camels mixed with camels imported from Sudan and Somalia. Local camels had significantly higher positive rates for MERS-CoVs and other CoVs than did imported camels (Pearson's $\chi^{2}$ test, $P<0.05$; tables S1 and S2).

Three $\mathrm{CoV}$ species were detected in dromedary camels: MERS-CoV (betacoronavirus, group $\mathrm{C}$ ); betacoronavirus 1 (betacoronavirus, group A); and human CoV 229E (alphacoronavirus) (fig. S1). Viruses from the latter two species are designated as camel $\beta 1-H K U 23-C o V s$ and camelid $\alpha$-CoVs, respectively. Although CoVs were detected almost year-round in these animals, a relatively higher preva-

Major outbreaks of Middle East respiratory syndrome (MERS) have been repeatedly reported in the Arabian Peninsula since 2012 and recently in South Korea (1-3), renewing concerns about potential changes in the mode of MERS coronavirus (CoV) transmission. Although increasing evidence suggests that dromedary camels are the most likely source of human infections (4-14), the prevalence and evolution of the MERS-CoV in this animal and the route of virus transmission to humans are not well defined, and little is known of other CoV species that may circulate in camels and how they might influence CoV ecology. lence of both MERS-CoV and camelid $\alpha-\mathrm{CoV}$ was observed from December 2014 to April 2015 (tables S1 and S2). Juvenile camels ( 0.5 to 1 year old) had the highest levels of respiratory infections with both the MERS-CoV and camelid $\alpha$ $\mathrm{CoV}$, followed by calves under 6 months, both at about twice the rate observed in camels aged 1 to 2 years (table S2). Younger camels seem to play a more important epidemiological role in maintaining both viruses, which is consistent with previous findings $(10,11,16,17)$.

The overall positive rates for MERS-CoV and camelid $\alpha$ CoV from nasal swabs were 12.1 and $19.8 \%$, respectively (ta- 
bles S1 and S2). However, only 3 of 304 camel rectal swabs were CoV-positive for either camelid $\alpha$ - or camel $\beta 1$-HKU23CoVs (tables S1 and S2). Thus, a major mode of virus shedding of the MERS- and camelid $\alpha-\mathrm{CoVs}$ is from the respiratory tract of dromedary camels. Over half of MERS-CoVpositive nasal swabs (56.6\%) were also positive for camelid $\alpha$-CoVs, indicating frequent co-infections of these viruses (tables S1 and S2). Nasal swabs from two animals contained all three species of CoVs detected in our survey. The high prevalence of these viruses suggests that they are enzootic in dromedary camels.

To examine the genetic diversity and evolution of the camel CoVs, metagenomic sequencing was carried out using the original swab materials that were positive in the initial RT-PCR screening. A total of 93 full-length viral genomes (67 MERS-CoVs, 25 camelid $\alpha$-CoVs, and one camel $\beta 1$ HKU23-CoV) were obtained from 79 nasal swab samples. Thirty-eight of these samples presented co-infections of MERS-CoV with one or both of the two other CoV species, but only 14 samples yielded two complete genomes.

$\beta 1-H K U 23-C o V s$ have been detected in camels in Dubai (18), and the camelid $\alpha$-CoVs are closely related to a virus isolated from alpacas in California in 2007 (fig. S1) (19, 20). The camelid $\alpha$-CoVs clustered with the human $\mathrm{CoV} 229 \mathrm{E}$ (fig. S1), a causal agent of common colds in humans. The high prevalence of asymptomatic infections with camelid $\alpha$ CoVs in Saudi Arabian camels emphasizes the important role this species plays in CoV ecology.

Recombination has been reported in the MERS-CoV species $(21,22)$. Phylogenetic analysis of the MERS-CoV fullgenome sequences obtained in this study $(n=67)$, together with those available in public databases $(n=106)$, revealed recombination signatures that defined five major phylogenetically stable lineages, all of which contained human and camel MERS-CoV sequences (Fig. 1 and figs. S2 and S3). A few viruses that showed inconsistent topologies in subgenomic trees, suggesting that they have a more varied history of recombination, were not classified within the five main lineages (fig. S2). MERS-CoVs from Saudi Arabian camels were found within each of the five lineages; the viruses sequenced in this study fell into lineages 3, 4, and 5, with the exception of some minor recombinants (Figs. 1 and 2 and figs. S2 and S3). Thus, the evolution of MERS-CoVs within camels has led to diverse lineages that have all caused human infections, indicating that there is a low barrier for interspecies transmission.

MERS-CoVs obtained between July and December 2014 mainly fell into lineages 3 and 5, whereas those from 2015 were principally from lineage 5 (Fig. 2 and figs. S2 and S3). Four viruses sampled during December 2014, which showed evidence of a small recombinant region, and a virus from March 2015 belonged to lineage 4 (Fig. 2 and figs. S2 to S4). Viruses from lineage 5, which are associated with the Korean outbreak and the recent human infections in Riyadh (Fig. 1) (3), were first identified in our surveillance in July
2014 and have been predominant in Saudi Arabian camels since November 2014. However, all of the human viruses of this lineage were reported from February 2015 onward. The MERS-CoV variants associated with the recent outbreak of human infections in South Korea [e.g., ChinaGD01-v1/2015 and KOR/KNIH/002-05/2015 $(23,24)]$ show the highest similarity (99.96 to $99.98 \%$, full genome) to a camel virus (Camel/Riyadh/Ry159/2015) sampled in March 2015 (Fig. 1 and figs. S2 and S3).

A statistically significant signal for phylogenetic incongruence in lineage 5 defined two recombinant sources of the MERS-CoV genome: (i) positions 1 to 16,173 and 24,191 to end, and (ii) 16,174 to 24,190 (Fig. 1). The phylogeny indicates that lineage 5 viruses evolved from a recombinant virus that acquired the $5^{\prime}$ part of ORFlab and the $3^{\prime}$ part of the $\mathrm{S}$ (spike) gene from lineage 4 and the remaining genomic regions from lineage 3 (Fig. 1C). In both subgenomic phylogenies, lineage 5 viruses were closely related to lineage 3 and 4 viruses from Saudi Arabian camels, suggesting that they hosted this recombination event. Ten synonymous nucleotide changes and a Thr6381Ala amino acid substitution in the nsp14-exonuclease of the ORF1ab polyprotein, relative to lineage 3 , were due to the recombination in lineage 5 (Fig. 1A). The possible function of these substitutions requires further investigation. A molecular clock dating analysis indicates that the recombination event probably occurred between December 2013 and June 2014 (fig. S5). Nine other putative MERS-CoV recombinant strains (fig. S4) were seemingly generated by sporadic events and have not persisted in the population, or may represent mixed infections of MERS-CoV strains from different lineages. Although frequent co-infections of MERS- and camelid $\alpha$-CoVs were observed (tables S1 and S2), no evidence of recombination among them was identified.

Four CoV species circulate widely in humans, and two others have caused severe sporadic infections with limited human-to-human transmission $(1,25)$. The wide species range of CoVs and their propensity to cross species boundaries suggest that more will emerge in the future. Since the first report of MERS in $2012(1,2)$, the causative virus has been transmitted to over 25 countries, mostly by international travelers that have been to the Middle East (3). Even though a high prevalence of MERS-CoVs has been detected in this work and in previous studies of dromedary camels (4-14), limited quarantine and biosecurity measures are in place to reduce the exposure of humans to the virus, and more cases must be expected in the future. The recent outbreak of MERS in Korea (3) shows that MERS-CoVs have the ability to cause large outbreaks in environments that are different from the Middle East. Although changes in human population density, climate conditions, and social factors may contribute to the spread of MERS-CoVs in other regions, the prevention of transmission at the animal/human interface is likely to be the most efficient measure to contain the threat from this virus. 


\section{REFERENCES AND NOTES}

1. A. M. Zaki, S. van Boheemen, T. M. Bestebroer, A. D. Osterhaus, R. A. Fouchier, Isolation of a novel coronavirus from a man with pneumonia in Saudi Arabia. $N$. Engl. J. Med. 367, 1814-1820 (2012). Medline doi:10.1056/NEJMoa1211721

2. A. Bermingham, M. A. Chand, C. S. Brown, E. Aarons, C. Tong, C. Langrish, K. Hoschler, K. Brown, M. Galiano, R. Myers, R. G. Pebody, H. K. Green, N. L. Boddington, R. Gopal, N. Price, W. Newsholme, C. Drosten, R. A. Fouchier, M. Zambon, Severe respiratory illness caused by a novel coronavirus, in a patient transferred to the United Kingdom from the Middle East, September 2012. Euro Surveill. 17, 20290 (2012). Medline

3. World Health Organization, Middle East Respiratory Syndrome Coronavirus (MERSCoV) (2015); http://www.who.int/emergencies/mers-cov/en/.

4. C. B. E. M. Reusken, B. L. Haagmans, M. A. Müller, C. Gutierrez, G.-J. Godeke, B. Meyer, D. Muth, V. S. Raj, L. Smits-De Vries, V. M. Corman, J.-F. Drexler, S. L. Smits, Y. E. El Tahir, R. De Sousa, J. van Beek, N. Nowotny, K. van Maanen, E. Hidalgo-Hermoso, B.-J. Bosch, P. Rottier, A. Osterhaus, C. Gortázar-Schmidt, C. Drosten, M. P. G. Koopmans, Middle East respiratory syndrome coronavirus neutralising serum antibodies in dromedary camels: A comparative serological study. Lancet Infect. Dis. 13, 859-866 (2013). Medline doi:10.1016/S14733099(13)70164-6

5. A. N. Alagaili, T. Briese, N. Mishra, V. Kapoor, S. C. Sameroff, P. D. Burbelo, E. de Wit, V. J. Munster, L. E. Hensley, I. S. Zalmout, A. Kapoor, J. H. Epstein, W. B. Karesh, P. Daszak, O. B. Mohammed, W. I. Lipkin, Middle East respiratory syndrome coronavirus infection in dromedary camels in Saudi Arabia. MBio 5, e00884-14 (2014).Medline doi:10.1128/mBio.01002-14

6. E. I. Azhar, S. A. El-Kafrawy, S. A. Farraj, A. M. Hassan, M. S. Al-Saeed, A. M. Hashem, T. A. Madani, Evidence for camel-to-human transmission of MERS coronavirus. N. Engl. J. Med. 370, 2499-2505 (2014)._Medline doi:10.1056/NEJMoa1401505

7. M. G. Hemida, R. A. Perera, P. Wang, M. A. Alhammadi, L. Y. Siu, M. Li, L. L. Poon, L. Saif, A. Alnaeem, M. Peiris, Middle East Respiratory Syndrome (MERS) coronavirus seroprevalence in domestic livestock in Saudi Arabia, 2010 to 2013. Euro Surveill. 18, 20659 (2013). Medline doi:10.2807/15607917.ES2013.18.50.20659

8. B. Meyer, M. A. Müller, V. M. Corman, C. B. Reusken, D. Ritz, G. J. Godeke, E. Lattwein, S. Kallies, A. Siemens, J. van Beek, J. F. Drexler, D. Muth, B. J. Bosch, U. Wernery, M. P. Koopmans, R. Wernery, C. Drosten, Antibodies against MERS coronavirus in dromedary camels, United Arab Emirates, 2003 and 2013. Emerg. Infect. Dis. 20, 552-559 (2014). Medline doi:10.3201/eid2004.131746

9. B. L. Haagmans, S. H. Al Dhahiry, C. B. Reusken, V. S. Raj, M. Galiano, R. Myers, G. J. Godeke, M. Jonges, E. Farag, A. Diab, H. Ghobashy, F. Alhajri, M. Al-Thani, S. A. Al-Marri, H. E. Al Romaihi, A. Al Khal, A. Bermingham, A. D. Osterhaus, M. M. AlHajri, M. P. Koopmans, Middle East respiratory syndrome coronavirus in dromedary camels: An outbreak investigation. Lancet Infect. Dis. 14, 140-145 (2014). Medline doi:10.1016/S1473-3099(13)70690-X

10. U. Wernery, V. M. Corman, E. Y. Wong, A. K. Tsang, D. Muth, S. K. Lau, K. Khazanehdari, F. Zirkel, M. Ali, P. Nagy, J. Juhasz, R. Wernery, S. Joseph, G. Syriac, S. K. Elizabeth, N. A. Patteril, P. C. Woo, C. Drosten, Acute Middle East respiratory syndrome coronavirus infection in livestock dromedaries, Dubai, 2014. Emerg. Infect. Dis. 21, 1019-1022 (2015)._. Medline doi:10.3201/eid2106.150038

11. A. I. Khalafalla, X. Lu, A. I. Al-Mubarak, A. H. Dalab, K. A. Al-Busadah, D. D. Erdman, MERS-CoV in upper respiratory tract and lungs of dromedary camels, Saudi Arabia, 2013-2014. Emerg. Infect. Dis. 21, 1153-1158 (2015). Medline doi:10.3201/eid2107.150070

12. D. R. Adney, N. van Doremalen, V. R. Brown, T. Bushmaker, D. Scott, E. de Wit, R. A. Bowen, V. J. Munster, Replication and shedding of MERS-CoV in upper respiratory tract of inoculated dromedary camels. Emerg. Infect. Dis. 20, 19992005 (2014). Medline doi:10.3201/eid2012.141280

13. M. A. Müller, B. Meyer, V. M. Corman, M. Al-Masri, A. Turkestani, D. Ritz, A. Sieberg, S. Aldabbagh, B. J. Bosch, E. Lattwein, R. F. Alhakeem, A. M. Assiri, A. M. Albarrak, A. M. Al-Shangiti, J. A. Al-Tawfiq, P. Wikramaratna, A. A. Alrabeeah, C. Drosten, Z. A. Memish, Presence of Middle East respiratory syndrome coronavirus antibodies in Saudi Arabia: A nationwide, cross-sectional, serological study. Lancet Infect. Dis. 15, 559-564 (2015)._Medline doi:10.1016/S1473-3099(15)70090-3

14. R. A. Perera, P. Wang, M. R. Gomaa, R. El-Shesheny, A. Kandeil, O. Bagato, L. Y. Siu, M. M. Shehata, A. S. Kayed, Y. Moatasim, M. Li, L. L. Poon, Y. Guan, R. J.
Webby, M. A. Ali, J. S. Peiris, G. Kayali, Seroepidemiology for MERS coronavirus using microneutralisation and pseudoparticle virus neutralisation assays reveal a high prevalence of antibody in dromedary camels in Egypt, June 2013. Euro Surveill. 18, 20574 (2013).Medline doi:10.2807/1560-7917.ES2013.18.36.20574

15. Materials and methods are available as supplementary materials on Science Online.

16. E. A. Farag, C. B. Reusken, B. L. Haagmans, K. A. Mohran, V. Stalin Raj, S. D. Pas, J. Voermans, S. L. Smits, G. J. Godeke, M. M. Al-Hajri, F. H. Alhajri, H. E. AlRomaihi, H. Ghobashy, M. M. El-Maghraby, A. M. El-Sayed, M. H. Al Thani, S. AlMarri, M. P. Koopmans, High proportion of MERS-CoV shedding dromedaries at slaughterhouse with a potential epidemiological link to human cases, Qatar 2014. Infect. Ecol. Epidemiol. 5, 28305 (2015)._Medline doi:10.3402/iee.v5.28305

17. V. M. Corman, J. Jores, B. Meyer, M. Younan, A. Liljander, M. Y. Said, I. Gluecks, E. Lattwein, B. J. Bosch, J. F. Drexler, S. Bornstein, C. Drosten, M. A. Müller, Antibodies against MERS coronavirus in dromedary camels, Kenya, 1992-2013. Emerg. Infect. Dis. 20, 1319-1322 (2014).Medline doi:10.3201/eid2008.140596

18. P. C. Woo, S. K. Lau, U. Wernery, E. Y. Wong, A. K. Tsang, B. Johnson, C. C. Yip, C. C. Lau, S. Sivakumar, J. P. Cai, R. Y. Fan, K. H. Chan, R. Mareena, K. Y. Yuen, Novel betacoronavirus in dromedaries of the Middle East, 2013. Emerg. Infect. Dis. 20, 560-572 (2014). Medline doi:10.3201/eid2004.131769

19. B. M. Crossley, R. E. Mock, S. A. Callison, S. K. Hietala, Identification and characterization of a novel alpaca respiratory coronavirus most closely related to the human coronavirus 229E. Viruses 4, 3689-3700 (2012). Medline doi: $10.3390 / v 4123689$

20. B. M. Crossley, B. C. Barr, K. G. Magdesian, M. Ing, D. Mora, D. Jensen, A. P. Loretti, T. McConnell, R. Mock, Identification of a novel coronavirus possibly associated with acute respiratory syndrome in alpacas (Vicugna pacos) in California, 2007. J. Vet. Diagn. Invest. 22, 94-97 (2010). Medline doi:10.1177/104063871002200118

21. G. Dudas, A. Rambaut, http://biorxiv.org/content/early/2015/06/12/020834 (2015).

22. V. M. Corman, N. L. Ithete, L. R. Richards, M. C. Schoeman, W. Preiser, C Drosten, J. F. Drexler, Rooting the phylogenetic tree of Middle East respiratory syndrome coronavirus by characterization of a conspecific virus from an African bat. J. Virol. 88, 11297-11303 (2014). Medline doi:10.1128/JVI.01498-14

23. Q. Xie, Y. Cao, J. Su, X. Wu, C. Wan, C. Ke, W. Zhao, B. Zhang, Genomic sequencing and analysis of the first imported Middle East Respiratory Syndrome Coronavirus (MERS CoV) in China. Sci. China Life Sci. 58, 818-820 (2015). Medline doi:10.1007/s11427-015-4903-7

24. Y. J. Kim, Y. J. Cho, D. W. Kim, J. S. Yang, H. Kim, S. Park, Y. W. Han, M. R. Yun, H. S. Lee, A. R. Kim, D. R. Heo, J. A. Kim, S. J. Kim, H. D. Jung, N. Kim, S. H. Yoon, J. G. Nam, H. J. Kang, H. M. Cheong, J. S. Lee, J. Chun, S. S. Kim, Complete genome sequence of Middle East Respiratory Syndrome Coronavirus KOR/KNIH/002_05_2015, isolated in South Korea. Genome Announc. 3, e00787-e15 (2015). Medline

25. R. J. de Groot, S. C. Baker, R. S. Baric, C. S. Brown, C. Drosten, L. Enjuanes, R. A. Fouchier, M. Galiano, A. E. Gorbalenya, Z. A. Memish, S. Perlman, L. L. Poon, E. J. Snijder, G. M. Stephens, P. C. Woo, A. M. Zaki, M. Zambon, J. Ziebuhr, Middle East respiratory syndrome coronavirus (MERS-CoV): Announcement of the Coronavirus Study Group. J. Virol. 87, 7790-7792 (2013)._Medline doi:10.1128/JVl.01244-13

26. V. M. Corman, I. Eckerle, T. Bleicker, A. Zaki, O. Landt, M. Eschbach-Bludau, S. van Boheemen, R. Gopal, M. Ballhause, T. M. Bestebroer, D. Muth, M. A. Müller, J. F. Drexler, M. Zambon, A. D. Osterhaus, R. M. Fouchier, C. Drosten, Detection of a novel human coronavirus by real-time reverse-transcription polymerase chain reaction. Euro Surveill. 17, 20285 (2012). Medline

27. D. Wang, A. Urisman, Y. T. Liu, M. Springer, T. G. Ksiazek, D. D. Erdman, E. R. Mardis, M. Hickenbotham, V. Magrini, J. Eldred, J. P. Latreille, R. K. Wilson, D. Ganem, J. L. DeRisi, Viral discovery and sequence recovery using DNA microarrays. PLOS Biol. 1, E2 (2003). Medline

28. B. Chevreux, T. Pfisterer, B. Drescher, A. J. Driesel, W. E. Müller, T. Wetter, S. Suhai, Using the miraEST assembler for reliable and automated mRNA transcript assembly and SNP detection in sequenced ESTs. Genome Res. 14, 1147-1159 (2004). Medline doi:10.1101/gr.1917404

29. R. C. Edgar, MUSCLE: A multiple sequence alignment method with reduced time and space complexity. BMC Bioinformatics 5, 113 (2004)._Medline doi:10.1186/1471-2105-5-113 
30. S. Guindon, F. Delsuc, J. F. Dufayard, O. Gascuel, Estimating maximum likelihood phylogenies with PhyML. Methods Mol. Biol. 537, 113-137 (2009). Medline doi:10.1007/978-1-59745-251-9_6

31. S. Guindon, J. F. Dufayard, V. Lefort, M. Anisimova, W. Hordijk, O. Gascuel, New algorithms and methods to estimate maximum-likelihood phylogenies: Assessing the performance of PhyML 3.0. Syst. Biol. 59, 307-321 (2010). Medline doi:10.1093/sysbio/syq010

32. F. Ronquist, M. Teslenko, P. van der Mark, D. L. Ayres, A. Darling, S. Höhna, B. Larget, L. Liu, M. A. Suchard, J. P. Huelsenbeck, MrBayes 3.2: Efficient Bayesian phylogenetic inference and model choice across a large model space. Syst. Biol. 61, 539-542 (2012). Medline doi:10.1093/sysbio/sys029

33. D. Martin, E. Rybicki, RDP: Detection of recombination amongst aligned sequences. Bioinformatics 16, 562-563 (2000)._Medline doi:10.1093/bioinformatics/16.6.562

34. M. Padidam, S. Sawyer, C. M. Fauquet, Possible emergence of new geminiviruses by frequent recombination. Virology 265, 218-225 (1999)._Medline doi:10.1006/viro.1999.0056

35. D. Posada, K. A. Crandall, Evaluation of methods for detecting recombination from DNA sequences: Computer simulations. Proc. Natl. Acad. Sci. U.S.A. 98, 13757-13762 (2001). Medline doi:10.1073/pnas.241370698

36. J. M. Smith, Analyzing the mosaic structure of genes. J. Mol. Evol. 34, 126-129 (1992). Medline doi:10.1007/BF00182389

37. M. F. Boni, D. Posada, M. W. Feldman, An exact nonparametric method for inferring mosaic structure in sequence triplets. Genetics 176, 1035-1047 (2007).Medline doi:10.1534/genetics.106.068874

38. K. S. Lole, R. C. Bollinger, R. S. Paranjape, D. Gadkari, S. S. Kulkarni, N. G. Novak, R. Ingersoll, H. W. Sheppard, S. C. Ray, Full-length human immunodeficiency virus type 1 genomes from subtype C-infected seroconverters in India, with evidence of intersubtype recombination. J. Virol. 73, 152-160 (1999). Medline

39. H. Shimodaira, M. Hasegawa, Multiple comparisons of log-likelihoods with applications to phylogenetic inference. Mol. Biol. Evol. 16, 1114-1116 (1999). doi:10.1093/oxfordjournals.molbev.a026201

40. A. J. Drummond, M. A. Suchard, D. Xie, A. Rambaut, Bayesian phylogenetics with BEAUti and the BEAST 1.7. Mol. Biol. Evol. 29, 1969-1973 (2012). Medline doi:10.1093/molbev/mss075

41. T. T. Lam, J. Wang, Y. Shen, B. Zhou, L. Duan, C. L. Cheung, C. Ma, S. J. Lycett, C. Y. Leung, X. Chen, L. Li, W. Hong, Y. Chai, L. Zhou, H. Liang, Z. Ou, Y. Liu, A. Farooqui, D. J. Kelvin, L. L. Poon, D. K. Smith, O. G. Pybus, G. M. Leung, Y. Shu, R. G. Webster, R. J. Webby, J. S. Peiris, A. Rambaut, H. Zhu, Y. Guan, The genesis and source of the H7N9 influenza viruses causing human infections in China. Nature 502, 241-244 (2013). Medline doi:10.1038/nature12515

42. A. J. Drummond, S. Y. Ho, M. J. Phillips, A. Rambaut, Relaxed phylogenetics and dating with confidence. PLOS Biol. 4, e88 (2006). 10.1371/journal.pbio.0040088 Medline doi:10.1371/journal.pbio.0040088

43. V. N. Minin, E. W. Bloomquist, M. A. Suchard, Smooth skyride through a rough skyline: Bayesian coalescent-based inference of population dynamics. Mol. Biol. Evol. 25, 1459-1471 (2008). Medline doi:10.1093/molbev/msn090

44. A. Rambaut, M. A. Suchard, D. Xie, A. J. Drummond, Tracer v1.6; http://beast.bio.ed.ac.uk/Tracer (2014).

45. A. M. Somily, M. Barry, S. S. Al Subaie, A. A. BinSaeed, F. A. Alzami, W. Zaher, T. Al Qahtani, K. Al Jerian, S. J. N. McNabb, M. Cotten, S. J. Watson, S. Binter, A. Rambaut, P. Kellam, Evolution Patterns of the Middle East Respiratory Syndrome Coronavirus (MERS-CoV) Obtained from MERS Patients in Early 2015; http://virological.org/t/new-mers-cov-sequences-feb-mar-2015-andpreliminary-analysis/140 (2015).

46. M. Cotten, S. J. Watson, A. I. Zumla, H. Q. Makhdoom, A. L. Palser, S. H. Ong, A. A. Al Rabeeah, R. F. Alhakeem, A. Assiri, J. A. Al-Tawfiq, A. Albarrak, M. Barry, A. Shibl, F. A. Alrabiah, S. Hajjar, H. H. Balkhy, H. Flemban, A. Rambaut, P. Kellam, Z. A. Memish, Spread, circulation, and evolution of the Middle East respiratory syndrome coronavirus. MBio 5, e01062-13 (2014)._Medline doi:10.1128/mBio.01062-13

47. C. Drosten, D. Muth, V. M. Corman, R. Hussain, M. Al Masri, W. HajOmar, 0. Landt, A. Assiri, I. Eckerle, A. Al Shangiti, J. A. Al-Tawfiq, A. Albarrak, A. Zumla, A. Rambaut, Z. A. Memish, An observational, laboratory-based study of outbreaks of Middle East respiratory syndrome coronavirus in Jeddah and Riyadh, kingdom of Saudi Arabia, 2014. Clin. Infect. Dis. 60, 369-377 (2015). Medline doi:10.1093/cid/ciu812

\section{ACKNOWLEDGMENTS}

We thank C.-H. Yip, C.-L. Cheung, Y. Chai, C. Ma, T. Gan, Z. Jin, Z. Ou, P. Huang, J. Zhou, and G. Yu for technical assistance and P. Kellam, A. Bin Saeed, M. Cotten, M. A. Barry, and A. M. Somily for making sequences available before their formal publication. This study was supported by the Deanship of Scientific Research (DSR 46-130-35-HiCi) of King Abdulaziz University; by the Vice President for Educational Affairs A. O. Alyoubi under the umbrella of the Development Committee of Basic Sciences at King Abdulaziz University; by the Shenzhen Peacock Plan High-End Talents Program (award KQTD201203); and by the Li Ka Shing Foundation and Theme-based Research Scheme (award T11-705/14-N). E.C.H. is supported by an Australia Fellowship from the National Health and Medical Research Council of Australia (award AF30). All authors declare no competing financial interests. The sequences generated by this study were deposited in GenBank under accession numbers KT368824 to KT368916; additional data can be found in the supplementary materials.

\section{SUPPLEMENTARY MATERIALS}

www.sciencemag.org/cgi/content/full/science.aac8608/DC1

Materials and Methods

Figs. S1 to S5

Tables S1 and S2

References (26-47)

24 June 2015; accepted 12 November 2015

Published online 17 December 2015

10.1126/science.aac8608 

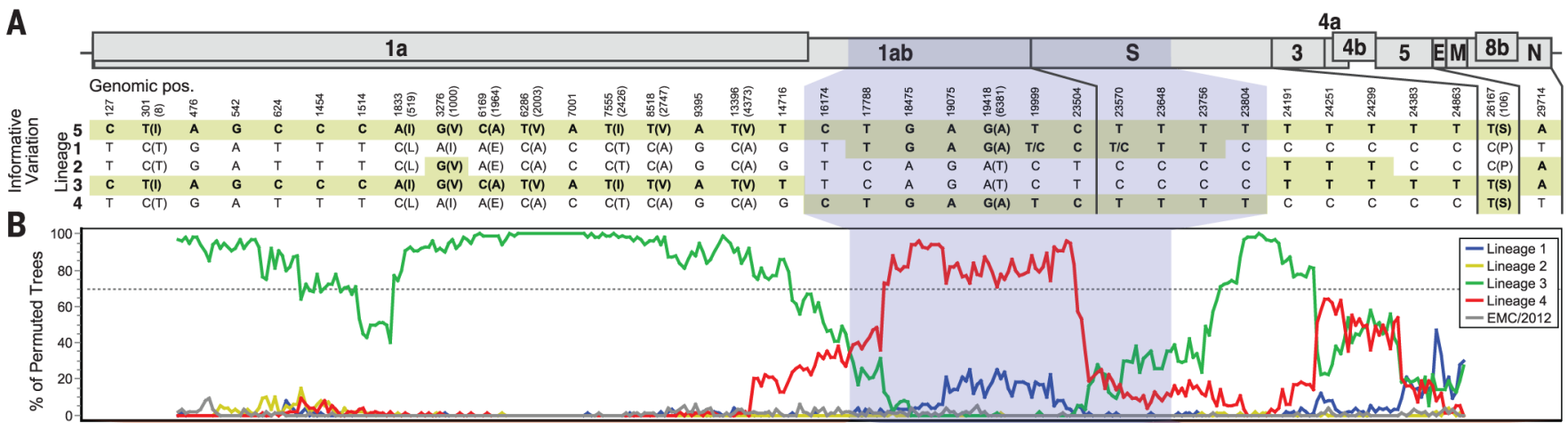

C

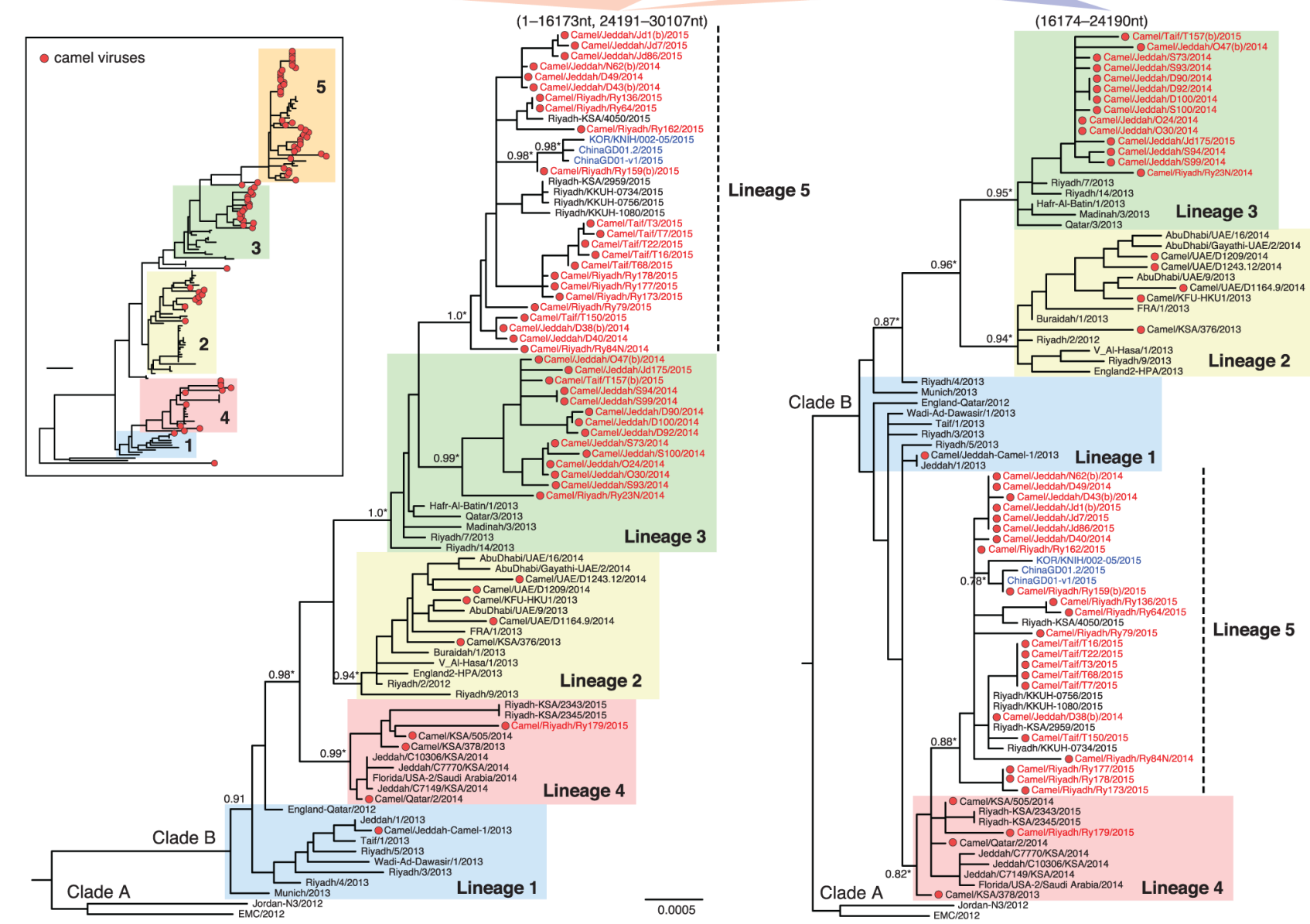

Fig. 1. Genomic recombination in MERS-CoVs. Only the variable sites (variants shared by more than two sequences; see the supplementary materials) were used for (A) and (B). (A) A rescaled structure of the MERSCoV genome (top) with consensus nucleotides, and any corresponding amino acid substitutions, that are phylogenetically informative in defining the lineages (bottom) (15). Nucleotides common with lineage 5 are highlighted (nucleotide substitution C26167T results in amino acid substitution P106S in ORF4b). The likely exchanged region is shaded blue. (B) Bootscanning recombination analysis based on the variable genomic sites. The dashed line indicates 70\% bootstrap support. (C) Maximum-likelihood phylogenetic trees inferred for the outer (left) and inner (right) nonrecombinant regions, indicating that lineage 5 is a recombinant of lineages 3 and 4. A subset of sequences from each lineage was used. Camel viruses are indicated by red circles; those sequenced in this study are shown in red text. Shimodaira-Hasegawa-like branch test values and Bayesian inference clade probabilities $>0.9$ (indicated by asterisks) are shown at selected lineages. Branch lengths reflect the number of nucleotide substitutions per site, and the trees were rooted by Camel/Egypt/NRCE-HKU205/2013. The inset tree was inferred using all available MERS-CoV genomic sequences $(n=164$; fig. S2).

Sciencexpress/ sciencemag.org/content/early/recent / 17 December 2015 / Page 5 / 10.1126/science.aac8606 

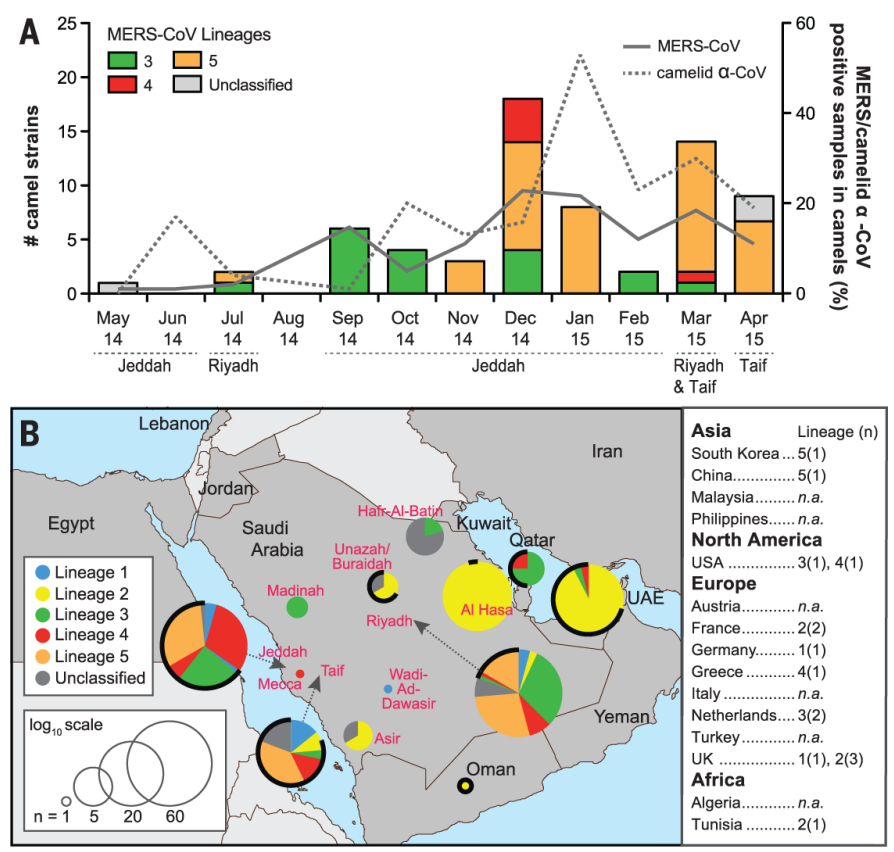

Fig. 2. Lineage distribution of MERS-CoV. Genetic lineages within MERS-CoVs were determined by phylogenetic analysis (fig. S3). (A) The bar chart shows the number of camel MERS-CoV sequences obtained, by lineage and month of sampling. Monthly percentages of samples positive for MERS or camelid $\alpha$-CoVs (determined by RT-PCR) are indicated by solid and dashed lines, respectively (right axis). Sampling sites are indicated below the sampling months. (B) Lineage distribution of all available MERS-CoV complete or partial genome sequences from countries that have reported MERS-CoV infections (n.a., sequence not available). For Saudi Arabia, counts are shown by city. In the pie charts, colors represent the lineages, and thick black edges indicate camel sequences. 